\title{
SPEED CONTROL OF A DC MOTOR USING A SIMPLE NEURO- CONTROLLER
}

\author{
Sanaa I. Amer, \\ Mahmoud M. Salem, \\ Yousry A.G. Atia \\ Electronics Research Institute \\ National Research Center, Dokki, Cairo, Egypt
}

\begin{abstract}
This paper presents an adaptive Single Neuro Control (SNC) of a separately excited dc motor. The control algorithm is implemented using Borland $\mathrm{C}++$ To validate the performance characteristics of the motor. Experimental verification for the SNC technique is performed. The proposed SNC scheme shows good agreement of both simulation and experimental results.

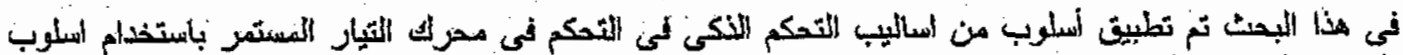

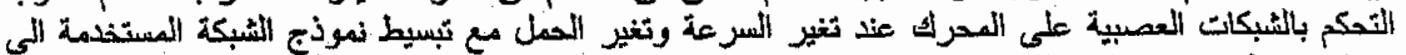

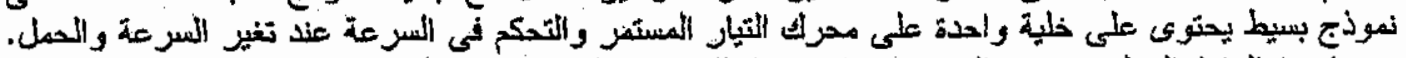

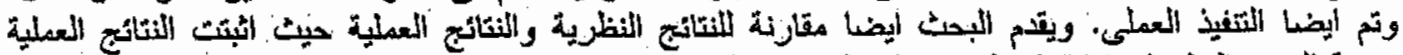

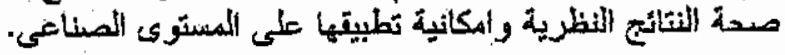

\section{INTRODUCTION}

During the past several years, Artificial Intelligent control has been growing rapidly in recent years. There are many researches for application of artificial intelligence in speed control; position control and current control is used. The ability of artificial neural networks to learn large classes of nonlinear functions is well known. It can be trained to emulate the unknown nonlinear plant dynamics by presenting a suitable set of input/output patternis generated by the plant. Once system dynamics have been identified using an ANN, many conventional control techniques can be applied to achieve the desired objective. An adaptive neural network speed controller for a separately-exited dc motor is presented incorporating on-line weights and biases updating. The ANN architecture is based on the inverse dynamic model of the nonlinear drive system and on-line operation begins from the start with random weights and biases. The back-propagation training technique adjusts the weights in all connecting links and biases in the nodes [1-3].

In this paper, a neural network controller for speed and current control of a separately excited dc motor is applied. The neural network technique used is a simplified version comprising one single neuron [3], thus eliminating the multi connection and reducing the computation time. This simplification was obtained by applying a modified error function in which the derivative of the error is included. The single neuron controller was experimentally implemented in the laboratory.

\section{SINGLE NEURO CONTROLLER PHILOSOPHY}

The neural network regulates the speed of the dc motor to track the reference value, through backpropagation algorithm by on-line tuning of the weights and biases in the different layers of the network, (the details of this controller are explained in reference [4]). For this reason a single neuro controller is used to reduce the computation time. The controller consists of only one weight and one neuron with a linear hard limit activation function as shown in figure (1).
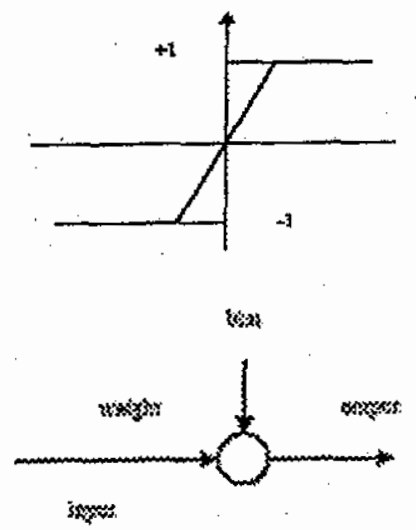

Fig. 1 Single neuron configuration and hard limit activation function 
The back propagation training algorithm is applied to the simple neuro-controller (SNC), its output can be derived as:

$$
\begin{aligned}
& u(\vec{n})=\pi(t) \\
& W(t)=W(i-1)+n * n C T
\end{aligned}
$$

Where, "WCT" is the neuron Weight Correction Term.

\section{$\eta$ : Learning rate}

W (t) : neuron weight

$\mathrm{u}(\mathrm{t})$ : neuron output

The weight correction term is given by [5]:

$$
\pi C T-\left[(r)-c(t)-k \frac{2(x)}{3}\right]
$$

Where:

$c(t)$ : the controlled variable

$r(t)$ : the controller input (reference input)

The weight change of the SNC based on the back propagation algorithm is given by:

$$
\Delta F=r * T C T
$$

The SNC weight update depends on $k$ and $\eta$; the two parameters are selected by trial and error. The selected SNC controller parameters are as follows: $\eta=.001$ and $\mathrm{k}=.01$

\section{DC MOTOR MODEL}

For this separately excited dc motor the field is constant and the armature controller depends on the armature voltage only. The dynamic equations are given below:

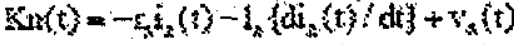

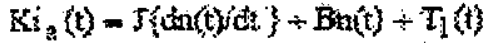

$$
\begin{aligned}
& \text { n (t) rotor speed rad /s } \\
& \mathrm{v} a \text { (t) terminal armature voltage } \mathrm{V} \\
& \text { i a (t) armature current } A \\
& \mathrm{~T} 1(\mathrm{t}) \text { load torque } \mathrm{Nm} \\
& \text { J rotor inertia } \mathrm{Nm} \\
& \mathrm{K} \text { torque \& back emf constant } \mathrm{Nm} \mathrm{A}^{-1} \\
& \text { B damping constant } \mathrm{Nm} \text { s } \\
& \mathrm{r}_{\mathrm{a}} \quad \text { armature resistance } \Omega \\
& l_{\mathrm{a}} \text { armature inductance } \mathrm{H}
\end{aligned}
$$

\section{SIMULATION RESULTS}

Figure (2) represents the block diagram of the controller system. Simulation results are obtained by a software simulator developed \{using Borland $\mathrm{C}++$.

Using Borland $\mathrm{CH}$ to apply the single neuro controller for separately excited dc motor, we obtained the resuits at change of speed and change of load torque. Figure (3) and figure (4) represent the simulation results with single neuro controller. Figure
(3) shows the speed and current response when the load torque is changed from stand still to $4 \mathrm{Nm}$ at 1000 rpm. Also, Figure (4) shows the speed and current response when the speed is changed from $1000 \mathrm{rpm}$ to $500 \mathrm{rpm}$ at constant load torque $4.5 \mathrm{Nm}$.

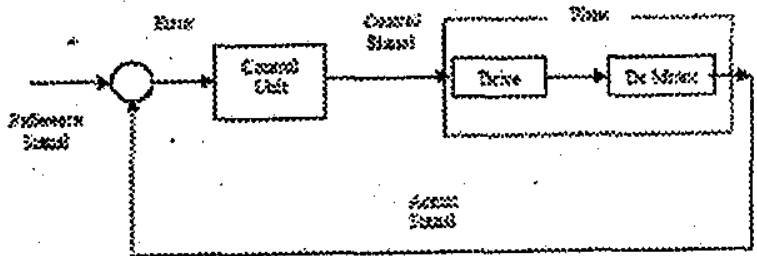

Fig.2 Block diagram of controller
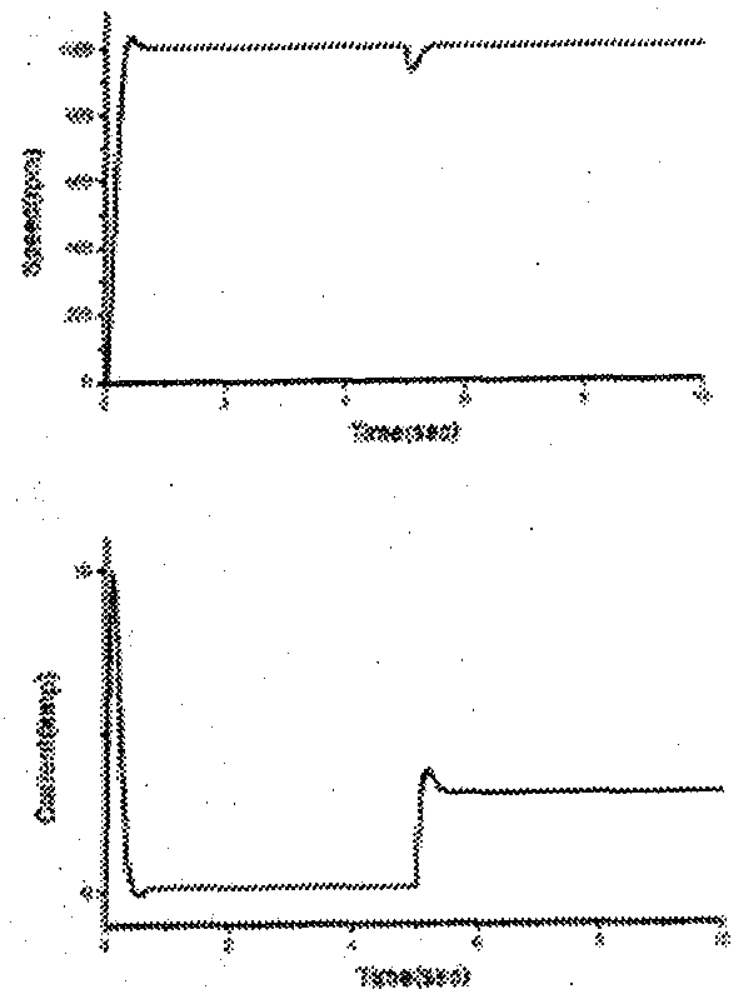

Fig. 3 Load torque changed form $0-4 \mathrm{Nm}$ at $1000 \mathrm{rpm}$

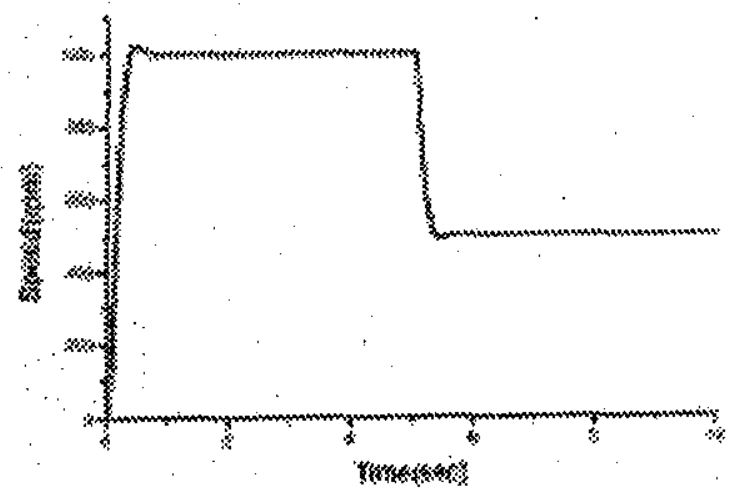




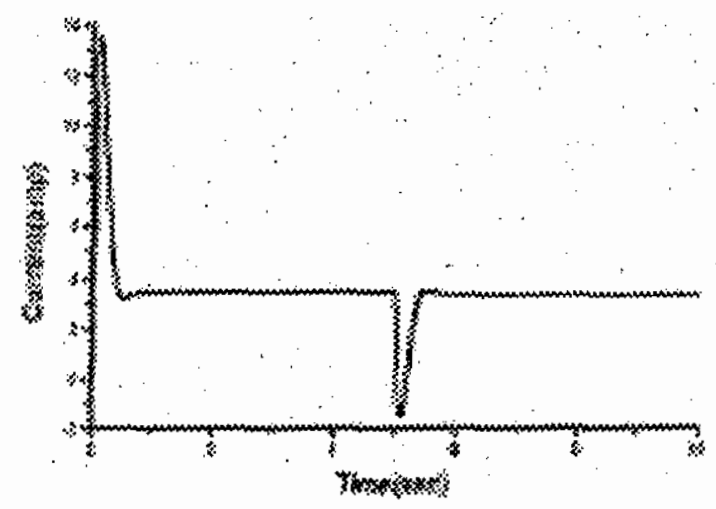

Fig. 4 Reference speed changed from 1000-500 rpm at $4.5 \mathrm{Nm}$

\section{EXPERIMENTAL WORK}

\subsection{Experimental Setup}

Figure (5) shows the experimental setup circuit for the system. The system consists of a single phase SCR rectifier bridge, the dc motor, load and torque meter, PC with SNC control algorithm, interfacing card, and 4-channel digital storage oscilloscope. The interface card is built in the Lab. using wire wrapping technique. The card contains $\mathrm{I} / \mathrm{O}$ digital lines, A/D and D/A chips.

The results are obtained for categories of disturbances, torque changes and speed changes. Torque changes mean that the reference speed is fixed but the load torque is suddenly changed, whereas speed changes means that the load torque is fixed but the reference speed is suddenly changed.

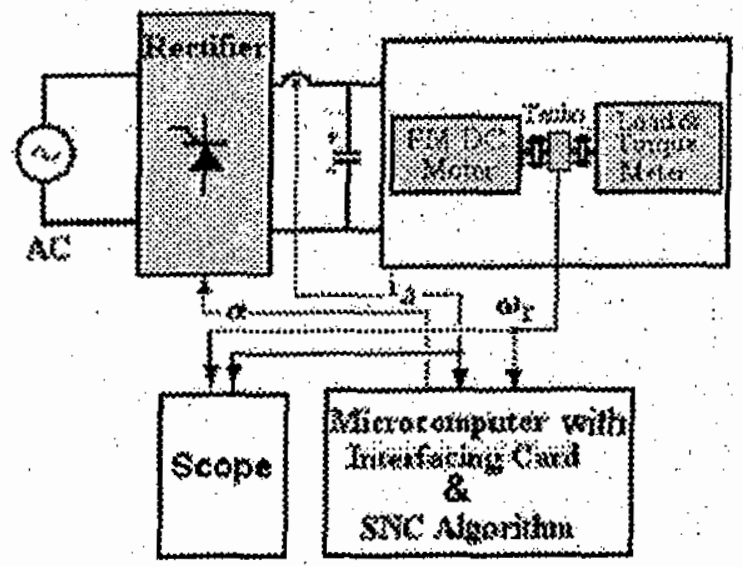

Fig. 5 Experimental work setup circuit

\subsection{Experimental Results}

The following are experimental results for the dc motor speed control with the single neuron.

\subsubsection{Torque changing}

Figures $(6,7)$ show the system response for a sudden change of load torque, whereas the reference speed is still unchanged. The upper trace is for the motor speed (350 $\mathrm{rmm} / \mathrm{div})$ and the lower is for the motor current (2.5A/div). In Figure (6) the reference speed is fixed at $1000 \mathrm{rpm}$ while the load torque is changed as $2-0-2 \mathrm{~N} . \mathrm{m}$. The controller maintains the speed constant with load variation and approximately zero steady state error. There is no speed overshoot with settling time about 1 second.

In Figure (7), the reference speed is $1000 \mathrm{rpm}$ while the load torque is changed as $4.5-0-4.5 \mathrm{~N} . \mathrm{m}$. Small dips are observed in the speed response at the load changes instants. There is a current overshoot at starting as the motor is loaded at starting, where after starting there is no overshoot or undershoot in speed or current.

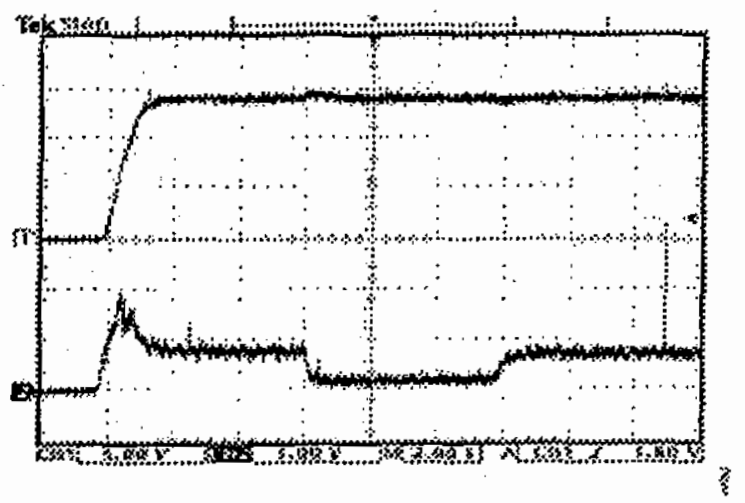

Fig. 6 At Reference Speed $1000 \mathrm{rpm}$ and 2-0-2 Nm .

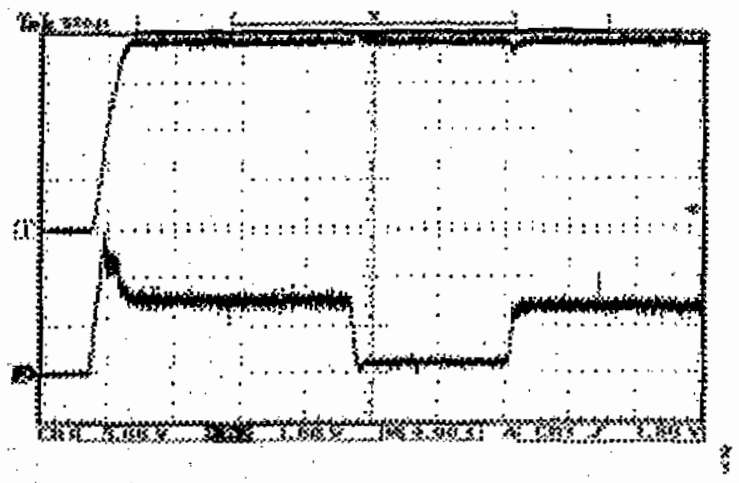

Fig. 7 At Reference Speed $1400 \mathrm{rpm}$ and 4.5-0-4.5 $\mathrm{Nm}$

\subsubsection{Speed changing}

In the following figures the motor reference speed is suddenly changed as follows: 0-250-750-1250-750$250 \mathrm{rpm}$. in Figure (8), and the load torque is hold at $4 \mathrm{~N} . \mathrm{m}$. during speed changing at $5.5 \mathrm{~N} . \mathrm{m}$. in Figure (9). There is no overshoot in speed response and the rising time is small, but in the falling of speed the falling time is slightly large because the dc power source is non energy acceptable source, so the stored. energy in the rotating parts take some time to dissipate. This is obvious in the current waveform during falling time. The current overshoot is proportional to the rising characteristics of the speed. 
As the speed is raised slowly the current overshoot becomes small. We can adjust the overshoot of the current by adjusting the speed response of the system.

These two figures and the previous two ones prove the superiority of the SNC controller at all operating conditions for speed or torque variations.

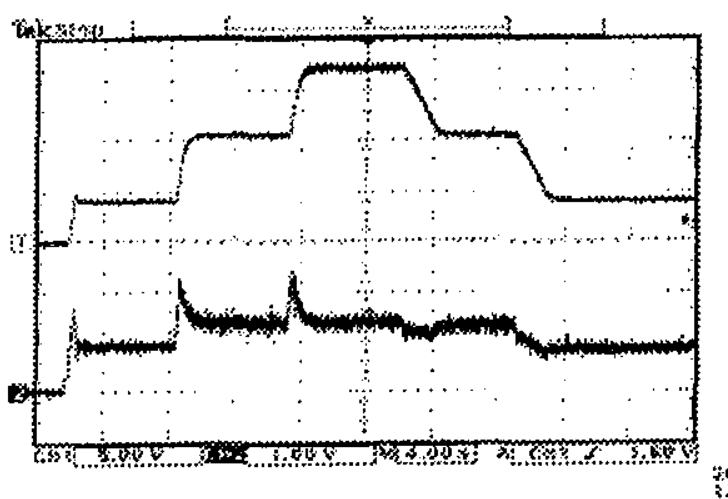

Fig. 8 Speed variations at $4 \mathrm{Nm}$

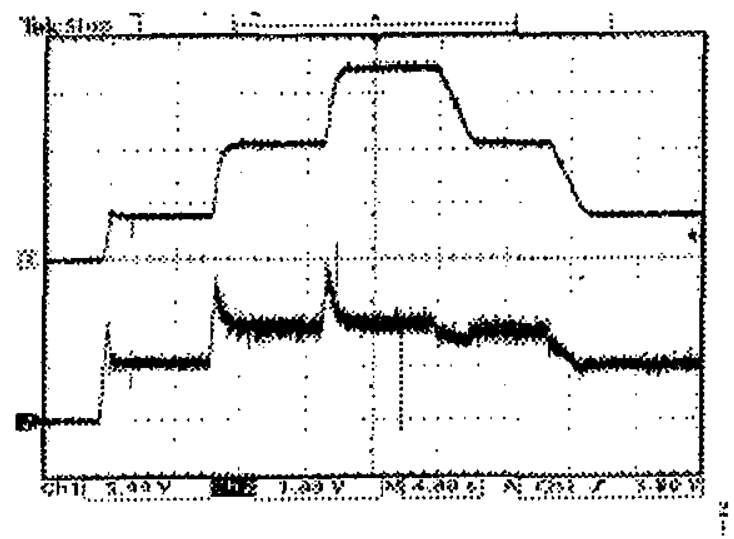

Fig. 9 Speed variations at $5.5 \mathrm{Nm}$

\section{COMPARISON BETWEEN SIMULATION AND EXPERIMENTAL RESULTS}

Experimental tests have been conducted out for motor operation with single neuro-controller. Figure (10) shows the simulation and experimental results for the current and motor speed for step change in the load torque from $6 \mathrm{Nm}$ to 0 to $6 \mathrm{Nm}$ at $1400 \mathrm{rpm}$ reference speed. Figure (11) shows the experimental results of the current and motor speed for step change in the reference speed at $2 \mathrm{Nm}$ load torque, we notice that there is small change in the current while the load torque is unchanged. This is due to the energy consumption in the instrumentation circuits (torque meter,...etc) which necessitates an increase in the load current.

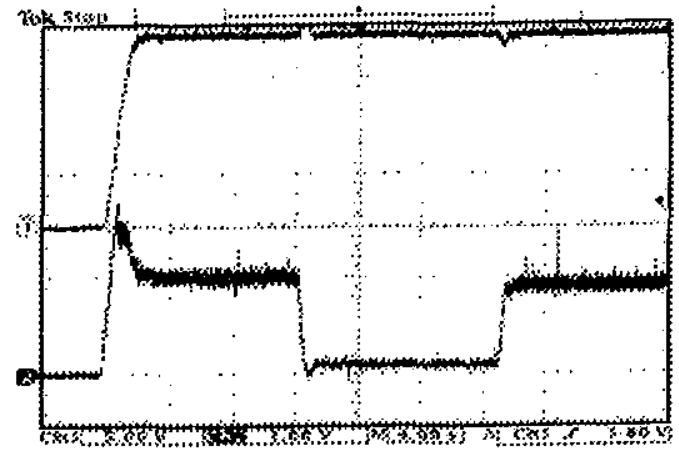

Experimental Results
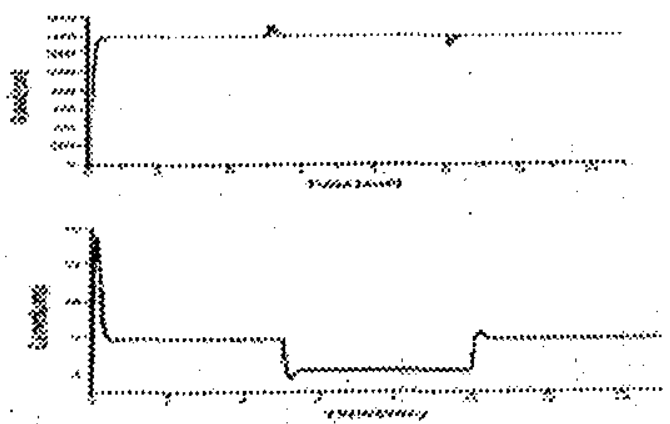

Simulation Results

Fig. 10 Load torque changed form $6-0-6 \mathrm{Nm}$ at 1400 rpm

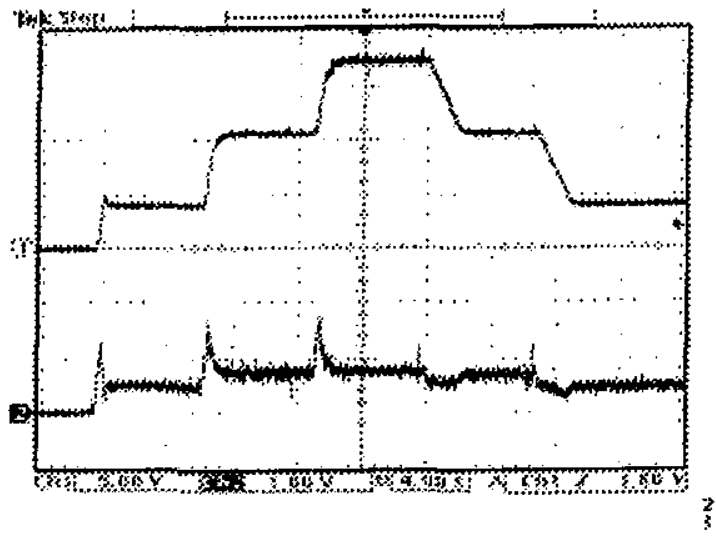

Experimental Results
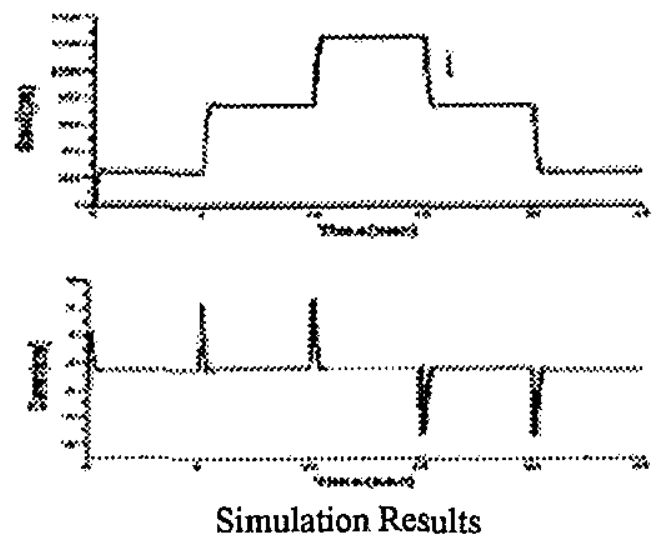

Fig. 11 Reference speed changed from 0-250-750$1250-750-250-0 \mathrm{rpm}$ at $2 \mathrm{Nm}$ 


\section{CONCLUSION}

This paper presented the implementation of a single neuro-controller for speed control of a separately. excited dc motor. The controller has the advantage of being independent of the controlled plant parameters. Therefore, changes in the operating conditions or in the system parameters did not affect the system performance. The single neuro-controller yields good transient response for a step change in the reference speed at constant load torque. Also, similar results were obtained for a step change in the load torque at constant reference speed. Good agreement between the theoretical and experimental results was found.

\section{REFERENCES}

[1] T. Fukuda and T. Shibata, "Theory and applications of Neural Networks for Industrial Control Systems", IEEE Transaction on Industrial Electronics, Vol.39,No.6, December 1992, pp.472-489.

[2] M. E. Elbuluk, L. Tong, and I. Husain; "NeuralNetwork-Based Model Reference Adaptive
Systems for High-Performance Motor Drives and Motion Controls" IEEE Transactions on Industry Applications, Vol.38, No.3, May/June 2002, pp. 879-886.

[3] S.I. Amer and M.M. Salem, "Comparison of Different Intelligent Control Techniques For a PM dc Motor ", Journal of Power Electronics, vol.5, No.1, January 2005, pp.1-10.

[4] A.M. Zaki, A.A. El- Sattar, S. Wahsh, H. M. Mashaly, and S. I. Amer, "Efficiency-Optimized Speed Control for a Separately-Excited DC Motor Using Adaptive Neurocontroller", 2nd IEEE International Conference on Power Electronics, Drives and Energy Systems, PEDES'98, Nov. 29-Dec. 3,1998,Perth, Australia.

[5] M.M. Salem, A.M. Zaki, O.A. Mahgoub, E. Abu El-Zahab, and O.P.Malik, "Experimental Studies with a Simple Neuro-Controller Based Excitation Controller", IEE proceeding on Generation, Transmission and Distribution, vol.145, No.1, Feb.2002, pp. 108-113. 